\title{
Influence of short-term dietary weight loss on cortisol secretion and metabolism in obese men
}

\author{
Alexandra M Johnstone, Peter Faber, Ruth Andrew ${ }^{1}$, Eileen R Gibney ${ }^{2}$, Marinos Elia ${ }^{3}$, Gerald Lobley, \\ $\mathrm{R}$ James Stubbs and Brian R Walker ${ }^{1}$ \\ Rowett Research Institute, Greenburn Road, Bucksburn, Aberdeen AB21 9SB, UK, ${ }^{1}$ Endocrinology Unit, University of Edinburgh, Western General \\ Hospital, Edinburgh EH4 2XU, UK, ${ }^{2}$ Human Nutrition Research Centre, Department of Biological and Nutritional Sciences, University of Newcastle, \\ Newcastle upon Tyne NE1 7RU, UK, ${ }^{3}$ Institute of Human Nutrition, Level C (113), West Wing, Southampton General Hospital, Tremona Road, \\ Southampton SO16 6YD, UK \\ (Correspondence should be addressed to Brian R Walker; Email: B.Walker@ed.ac.uk)
}

\begin{abstract}
Objectives: Obesity is associated with increased inactivation of cortisol by hepatic A-ring $5 \alpha$ - and $5 \beta$-reductases, impaired hepatic regeneration of cortisol from cortisone by $11 \beta$-hydroxysteroid dehydrogenase type 1 (11HSD1), but increased subcutaneous adipose 11HSD1 activity enhancing local cortisol levels in fat. Cause and effect between obesity and abnormal cortisol metabolism is untested. Design: Acute weight loss was induced by very low calorie diet (VLCD) or starvation in obese men. Methods: Otherwise healthy males (aged 20-55 years; body mass index (BMI) $30-40 \mathrm{~kg} / \mathrm{m}^{2}$ ) were studied after 6 days on a weight maintenance diet; then after either 6 days of starvation $(n=6)$ or 3 weeks of VLCD $(2.55 \mathrm{MJ} ; n=6)$; then after 1 week of weight maintenance; and finally after 2 weeks of being allowed to feed ad libitum. Plasma samples were obtained from indwelling cannulae at $0930 \mathrm{~h}$ and $1815 \mathrm{~h}$ and a $24 \mathrm{~h}$ urine collection was completed for analysis of cortisol metabolites by gas chromatography/mass spectrometry.

Results: Data are mean \pm S.E.M. BMI fell $\left(\mathrm{kg} / \mathrm{m}^{3}\right)$ from $34.8 \pm 0.8$ at baseline to $31.8 \pm 1.4$ on VLCD and $32.7 \pm 1.1$ on starvation. Starvation caused a rise in plasma cortisol (at $0930 \mathrm{~h}$ from $143 \pm 17$ to $216 \pm 11 \mathrm{nM}, P<0.001)$ but no change in total urinary cortisol metabolites. VLCD did not alter plasma cortisol and markedly reduced cortisol metabolite excretion (from $15.8 \pm 1.1 \mathrm{mg} / \mathrm{day}$ at baseline to $7.0 \pm 1.1 \mathrm{mg} /$ day, $P<0.001)$. Relative excretion of $5 \alpha$-reduced cortisol metabolites fell on both diets, but there were no changes in cortisol/cortisone metabolite ratios reflecting 11HSD activities. Conclusions: Weight loss with VLCD in obesity reverses up-regulation of hepatic A-ring reductases and normalises cortisol production rate; in contrast, starvation produces acute stress and further activation of cortisol secretion. We suggest that activation of cortisol secretion is not an irreversible intrinsic abnormality in obese patients, and speculate that dietary content has an important influence on the neuroendocrine response to weight loss.
\end{abstract}

European Journal of Endocrinology 150 185-194

\section{Introduction}

Idiopathic obesity has been associated with alterations in several neuroendocrine axes (1). Of particular interest is evidence for increased production of cortisol in men and women who are obese, which appears to be especially striking in those with central or abdominal obesity $(2,3)$. By analogy with the clinical consequences of increased cortisol secretion in Cushing's syndrome, these observations raise the possibility that increased cortisol production is of pathophysiological significance in idiopathic central obesity. However, to date no consistent abnormality of central control of the hypothalamic-pituitary-adrenal (HPA) axis has been observed which would explain increased cortisol secretion in obesity. Moreover, unlike patients with Cushing's syndrome, subjects with idiopathic obesity do not have markedly elevated plasma cortisol concentrations. Indeed, although there is some flattening of the diurnal rhythm (4), peak plasma cortisol in the morning is generally lower in obese subjects $(5,6)$. Lower plasma cortisol in the face of elevated cortisol production suggests that the metabolic clearance rate for cortisol is increased, and that activation of the HPA axis is compensatory. Enhanced clearance of cortisol in obesity has been demonstrated experimentally using labelled cortisol tracer $(7,8)$. More recent studies have attributed this, at least in part, to increased activity of enzymes which metabolise cortisol in the liver, particularly $5 \alpha$-reductase $(9,10)$. Nevertheless, although activation of the HPA axis secondary to increased cortisol metabolism does not increase circulating cortisol concentrations, it may have adverse effects, including increased adrenal androgen production (11). 
An additional level of complexity involves the influence of peripheral cortisol metabolism on intracellular cortisol concentrations within target tissues. Intracellular cortisol levels are modulated independently of circulating cortisol levels according to the activity of locally expressed enzymes. The clearest example is the influence of the two isozymes of $11 \beta$-hydroxysteroid dehydrogenase (11HSD) (12). 11HSD type 2 (11HSD2) inactivates cortisol to cortisone and is responsible for preventing cortisol gaining access to mineralocorticoid receptors, e.g. in distal nephron. 11HSD type 1 (11HSD1) catalyses reactivation of cortisone to cortisol in most, if not all, tissues where it is expressed (13). These include liver and adipose tissue, where reactivation of cortisol has a potent influence on local glucocorticoid receptor activation. 11HSD1 knockout mice show evidence of lower glucocorticoid activity in liver (reduced gluconeogenesis, increased lipid catabolism) and adipose tissue (decreased free fatty acid, increased leptin, and resistance to obesity on high-fat feeding) $(14,15)$. In contrast, mice with transgenic overexpression of 11HSD1 under the adipose-specific AP2 promoter have central obesity and its metabolic complications (hyperglycaemia, increased free fatty acids, insulin resistance) (16). In idiopathic obesity in man, tissue-specific disruption of 11HSD1 activity results in increased local generation of cortisol in subcutaneous adipose tissue $(17-20)$ but decreased cortisol in liver $(17,19,21)$. 11HSD1 has therefore been proposed as a key determinant of the metabolic consequences of obesity and a potentially exciting therapeutic target $(22-25)$.

The underlying mechanisms for these complex changes in cortisol metabolism in obesity are not known. In the Zucker obese rat, a model which recapitulates changes in A-ring reductases $(5 \alpha-$ and $5 \beta$-reductases) and 11HSD1 observed in human idiopathic obesity (26), altered glucocorticoid-metabolising enzymes are normalised by preventing weight gain by adrenalectomy (27). Whether differences in cortisol production or metabolism between lean and obese men and women reflect constitutive differences, or are secondary to weight gain, has not been tested. In the current study, to assess plasticity of cortisol metabolism and associated increased cortisol production in obesity, we examined effects of acute weight loss, induced by fasting or by very low calorie diet (VLCD), on cortisol production and metabolism in obese men.

\section{Subjects and methods}

\section{Participants}

Otherwise healthy, obese (body mass index (BMI) $30-40 \mathrm{~kg} / \mathrm{m}^{2}$ ) males aged $20-55$ years were recruited by newspaper advertisement. Subjects were only included if they were not on any special religious or prescribed diet; were non-smokers; had stable weight (weight change of no more than $2 \mathrm{~kg}$ in the previous 3 months); had normal medical examination, screening blood tests (full blood count, renal, liver and thyroid function) and electrocardiogram; and took no regular prescribed medication, vitamin or mineral supplements. These inclusion criteria were also checked with the participant's primary care physician. The study was approved by the Joint Ethical Committee of Grampian Health Board and the University of Aberdeen. Written informed consent was obtained.

\section{Study protocols}

Participants were admitted to the Human Nutrition Unit at the Rowett Research Institute, Aberdeen. They were resident in the Unit at night for the duration of the study (5-7 weeks), and during the daytime when calorimetry and other intensive measurements were being performed, but were allowed to leave the Unit during the day at other times to attend their workplace or home. All food and drink consumed during weight loss and weight maintenance was supplied by dietetic staff in the Unit, with food weighed before and after consumption to determine intake.

On days 1-6 (maintained baseline period), subjects consumed a mandatory maintenance diet (13\% protein, $30 \%$ fat and $57 \% \mathrm{CHO})$, calculated to meet energy requirements (estimated at $1.6 \times$ resting metabolic rate, RMR). Following this, subjects were allocated randomly to one of two weight loss diets, either starvation for 6 days or VLCD for 3 weeks (weight loss period). Starvation was intended to lose $\sim 5 \%$ of original body weight; VLCD was intended to lose $\sim 10 \%$ of original body weight. During starvation, subjects were only allowed to consume water. The VLCD comprised: daily weight $642 \mathrm{~g}$, energy $2.55 \mathrm{MJ}$, protein $49.4 \mathrm{~g}(0.84 \mathrm{MJ})$, carbohydrate $0.85 \mathrm{MJ}$, and fat $0.85 \mathrm{MJ}$. After the period of weight loss, subjects were maintained at their new lower body weight for 1 week (reduced weight maintenance period). During this time, subjects were fed a diet calculated at $1.4 \times$ RMR. Finally, subjects were studied while feeding ad libitum for 2 weeks, determining their own energy and nutrient intake from a selection of 45 supermarket type foods, as previously described (28).

In order to maintain a habitual level of energy expenditure, the subjects had compulsory exercise targets to achieve every day during the weight loss periods. The starvation group volunteers had two cycling periods of $40 \mathrm{~min}$ at $65-75 \mathrm{~W}$ and two step box sessions to maintain energy expenditure at approximately 1.5$1.6 \times \mathrm{RMR}$, similar to an average everyday level of activity (29). This was necessary because subjects within the starvation group were resident in a wholebody calorimeter (dimensions, $3.5 \times 1.9 \times 2.2 \mathrm{~m}$ ) for the duration of the fast and were otherwise inactive. The VLCD group were not resident in the calorimeter throughout their weight loss period, and they exercised 
for $40 \mathrm{~min}$ per day on a bicycle ergometer (Tunturi, Helsinki, Finland) at 50-90 W. The volunteers were requested not to undertake any other strenuous physical activity during the study. Total $24 \mathrm{~h}$ energy expenditure was estimated from heart rate measurements (Polar Sports tester, Polar Electro Oy, Kempele, Finland) (30). To equate heart rate to energy expenditure, a regression line between these variables was established individually for each subject, weekly, by simultaneously measuring heart rate, breath-by-breath $\mathrm{VO}_{2}$ and $\mathrm{VCO}_{2}$ (Vmax29 metabolic cart, Sensor Medics, Yarba Linda, CA, USA) at incremental workloads, on a bicycle ergometer (Tunturi E850, Tunturi, Finland), using the modified FLEX method (31).

\section{Clinical measurements}

Subject height was measured to the nearest $0.1 \mathrm{~cm}$ using a stadiometer (Holtain Ltd Crymych, Dyfed, Wales, UK). Body weight was measured daily, to the nearest $50 \mathrm{~g}$, by a member of staff, before eating and after emptying the bladder, with subjects wearing the same dressing gown each morning on a portable digital scale (DIGI DS-410, CMS Weighing Equipment, London, UK). Body composition was assessed by a four-compartment model (32), including dual energy X-ray absorptiometry scanning (DEXA; Norland XR26, Mark II-high speed pencil beam scanner, Norland Corporation, White Plains, NY, USA, equipped with dynamic filtration, with version 2.5.2 of the Norland software), air displacement whole body plethysmography (BodPod Body Composition System, Life Measurement Instruments, Concord, CT, USA), and total body water by deuterium dilution (33).

Compliance with the dietary regime was monitored by daily body weight, respiratory quotient (RQ) and plasma concentrations of $\beta$-hydroxybutyrate and glucose (data not shown).

For assessment of cortisol metabolites, a $24 \mathrm{~h}$ urine collection was obtained in both groups at the end of the baseline period, after $5 \%$ weight loss, and at the end of 2 weeks of feeding ad libitum. In addition, in the VLCD group, urine was collected after 10\% weight loss, and at the end of the reduced maintenance period after weight loss. Blood samples were obtained from indwelling cannulae for plasma cortisol and corticosteroid binding globulin (CBG) measurement at $0900 \mathrm{~h}$ and $1815 \mathrm{~h}$ in both groups at the end of the baseline period, after 5\% weight loss, and at the end of the weight maintenance period.

\section{Laboratory measurements}

Plasma cortisol (34) and CBG (Medgenix Diagnostics, Brussels, Belgium) were measured by radioimmunoassays. Cortisol and its metabolites were measured in urine by electron impact gas chromatography/mass spectrometry following Sep-Pak C18 extraction, hydrolysis with $\beta$-glucuronidase, and formation of the methoxime-trimethylsilyl derivatives (35). Epi-cortisol and epi-tetrahydrocortisol were used as internal standards. Total cortisol metabolite excretion was calculated as tetrahydrocortisols (THFs) + tetrahydrocortisone (THE) + cortols + cortolones (36) (Fig. 1). Relative metabolism by $5 \alpha$ - and $5 \beta$-reductases were inferred from the $5 \beta$-THF $/ 5 \alpha$-THF ratio. A-ring reduction of cortisol was inferred from the ratios of THFs/cortisol (37) and $5 \beta$-reductase activity from the ratio of THE/cortisone. Whole-body equilibrium between cortisol and cortisone, determined by the balance of tissue-specific activities of $11 \beta$-reductase and $11 \beta$-dehydrogenase activities, was inferred from the ratio of THFs/THE. Renal 11 $\beta$-dehydrogenase activity was inferred from the urinary free cortisol/cortisone ratio $(35,38)$.

\section{Statistics}

The starvation and VLCD studies were analysed independently. Data are expressed as mean \pm S.E.M., and were compared by repeated measures ANOVA with post hoc paired Student's $t$-tests where appropriate.

\section{Results}

\section{Weight loss and body composition}

Baseline characteristics of participants are shown in Table 1. Participants in the VLCD group tended to be older with higher \% body fat than participants in the

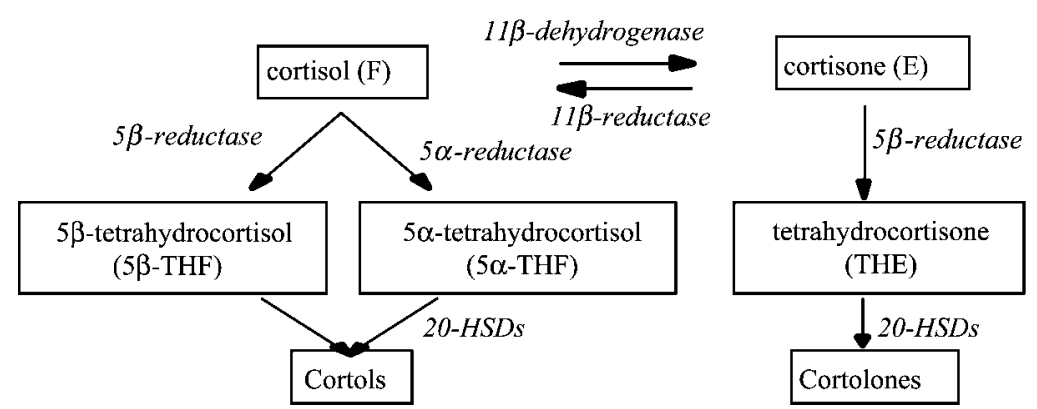

Figure 1 Principal pathways of metabolism of cortisol. 20 -HSDs $=20 \alpha$ - and $20 \beta$-hydroxysteroid dehydrogenases. 
Table 1 Baseline characteristics of participants.

\begin{tabular}{lcc}
\hline & Starvation study & VLCD study \\
\hline Number of men & 6 & $46 \pm 4(28-56)$ \\
Age (years) & $39 \pm 5(19-52)$ & $1.75 \pm 0.02(1.68-1.83)$ \\
Height $(\mathrm{m})$ & $1.76 \pm 0.02(1.67-1.84)$ & $107.3 \pm 6.1(85.2-124.1)$ \\
Body weight $(\mathrm{kg})$ & $107.2 \pm 4.7(93.8-123.5)$ & $34.9 \pm 1.4(30.3-39.5)$ \\
BMl $\left(\mathrm{kg} / \mathrm{m}^{2}\right)$ & $34.7 \pm 1.0(30.9-38.5)$ & $41.9 \pm 1.7(35.5-46.6)$ \\
Body fat $(\%$ of body weight) & $36.1 \pm 1.5(32.4-41.6)$ & $137 \pm 6(117-160)$ \\
Systolic blood pressure $(\mathrm{mmHg})$ & $118 \pm 2(117-122)$ & $86 \pm 6(69-95)$ \\
Diastolic blood pressure $(\mathrm{mmHg})$ & $77 \pm 3(68-85)$ & $5.8 \pm 0.2(5.5-6.5)$ \\
Fasting plasma glucose $(\mathrm{mM})$ & $5.3 \pm 0.2(4.7-5.8)$ & \\
\hline
\end{tabular}

Data are means \pm S.E.M. (range).

starvation study. Changes in body weight and \% body fat are shown in Table 2.

\section{Urinary cortisol metabolites}

VLCD was associated with reduced urinary excretion of cortisol and all of its principal metabolites (Fig. 2 and Table 3). This was progressive, with some reduction after 5\% weight loss, a further reduction after $10 \%$ weight loss, further reduction still during the week of weight maintenance diet, and then 'recovery' towards baseline values after 2 weeks of being allowed to feed ad libitum. VLCD also had effects on cortisol metabolism, as judged by ratios of urinary metabolites (Table 3). There was no change in ratios reflecting 11HSD activities (either cortisol/cortisone

Table 2 Changes in body composition measured using the four-compartment model (32).

\begin{tabular}{|c|c|c|c|}
\hline Measurement & Phase of study & Starvation & VLCD \\
\hline \multirow[t]{5}{*}{ Body weight (kg) } & Maintained basal & $107.2 \pm 4.7$ & $107.3 \pm 6.1$ \\
\hline & $5 \%$ weight loss & 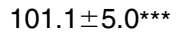 & $102.1 \pm 5.8^{* * *}$ \\
\hline & $10 \%$ weight loss & & $98.1 \pm 5.8^{\star * *}$ \\
\hline & Maintained weight loss & $102.4 \pm 4.9 * * *$ & $97.9 \pm 5.8^{\star \star \star}$ \\
\hline & Ad libitum & $100.6 \pm 5.0 * * *$ & $96.3 \pm 5.3^{\star \star \star}$ \\
\hline \multirow[t]{5}{*}{$\mathrm{BMI}\left(\mathrm{kg} / \mathrm{m}^{2}\right)$} & Maintained basal & $34.7 \pm 1.0$ & $34.9 \pm 1.4$ \\
\hline & $5 \%$ weight loss & $32.7 \pm 1.1^{* \star *}$ & $33.1 \pm 1.5^{\star \star \star}$ \\
\hline & $10 \%$ weight loss & & $31.8 \pm 1.5^{\star * *}$ \\
\hline & Maintained weight loss & $33.1 \pm 1.1^{* * *}$ & $31.8 \pm 1.5^{\star * *}$ \\
\hline & Ad libitum & $32.6 \pm 1.2^{* * *}$ & $31.2 \pm 1.4^{* * *}$ \\
\hline \multirow[t]{5}{*}{$\%$ Body fat } & Maintained basal & $36.1 \pm 1.5$ & $41.9 \pm 1.7$ \\
\hline & $5 \%$ weight loss & $35.0 \pm 1.4^{* * *}$ & $40.5 \pm 1.9 * * *$ \\
\hline & $10 \%$ weight loss & & $38.2 \pm 2.0^{* * *}$ \\
\hline & Maintained weight loss & $33.2 \pm 1.6^{* * *}$ & $36.9 \pm 2.2^{\star \star *}$ \\
\hline & Ad libitum & $32.5 \pm 1.8^{\star \star *}$ & $36.3 \pm 2.0^{\star \star *}$ \\
\hline \multirow[t]{5}{*}{ Fat mass $(\mathrm{kg})$} & Maintained basal & $38.8 \pm 2.7$ & $45.3 \pm 4.1$ \\
\hline & $5 \%$ weight loss & $35.5 \pm 2.6^{\star \star \star}$ & $41.7 \pm 3.9 * \star \star$ \\
\hline & $10 \%$ weight loss & & $37.9 \pm 3.9^{\star \star \star}$ \\
\hline & Maintained weight loss & $34.1 \pm 2.8^{\star \star *}$ & $36.4 \pm 3.9^{\star \star \star *}$ \\
\hline & Ad libitum & $33.0 \pm 3.2^{* * *}$ & $35.1 \pm 3.3^{\star \star \star}$ \\
\hline \multirow[t]{5}{*}{ Fat-free mass $(\mathrm{kg})$} & Maintained basal & $68.4 \pm 2.9$ & $62.0 \pm 2.8$ \\
\hline & $5 \%$ weight loss & $65.6 \pm 3.1^{* \star *}$ & $60.4 \pm 2.9 * * *$ \\
\hline & $10 \%$ weight loss & & $60.3 \pm 2.8^{* * *}$ \\
\hline & Maintained weight loss & $68.3 \pm 2.9$ & $61.5 \pm 3.1^{* \star *}$ \\
\hline & Ad libitum & $67.6 \pm 2.7$ & $61.1 \pm 3.3^{\star \star *}$ \\
\hline \multirow[t]{5}{*}{ Total body water (kg) } & Maintained basal & $50.8 \pm 1.9$ & $46.7 \pm 2.1$ \\
\hline & $5 \%$ weight loss & $47.6 \pm 2.3^{\star \star \star}$ & $45.4 \pm 2.3$ \\
\hline & $10 \%$ weight loss & & $44.8 \pm 2.3^{\star \star *}$ \\
\hline & Maintained weight loss & $50.1 \pm 2.1$ & $45.6 \pm 2.5$ \\
\hline & Ad libitum & $49.4 \pm 1.9$ & $45.4 \pm 2.5$ \\
\hline \multirow[t]{5}{*}{ Bone mineral mass $(\mathrm{kg})$} & Maintained basal & $3.42 \pm 0.1$ & $3.27 \pm 0.2$ \\
\hline & $5 \%$ weight loss & $3.38 \pm 0.1$ & $3.31 \pm 0.2$ \\
\hline & $10 \%$ weight loss & & $3.25 \pm 0.2$ \\
\hline & Maintained weight loss & $3.39 \pm 0.1$ & $3.30 \pm 0.2$ \\
\hline & Ad libitum & $3.39 \pm 0.1$ & $3.27 \pm 0.2$ \\
\hline
\end{tabular}

Data are means \pm S.E.M.

Versus maintained basal measurement: ${ }^{* \star \star} P<0.001$. 


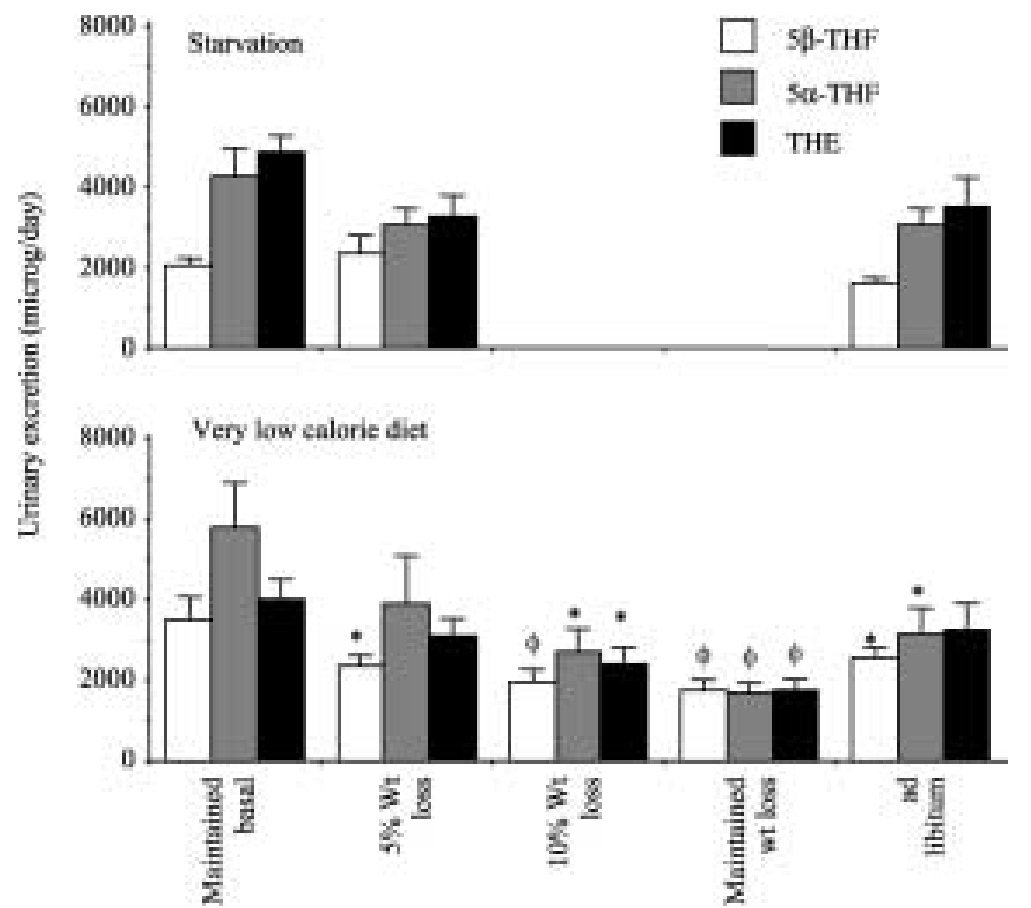

Figure 2 Twenty-four hour urinary cortisol metabolite excretion. Data are means \pm S.E.M. for $n=6$ subjects in the starvation study (upper panel) or the VLCD study (lower panel). By repeated measures ANOVA, differences were significant only following VLCD $\left(P<0.01\right.$ for $5 \beta$-THF, $P<0.02$ for $5 \alpha$-THF, $P<0.05$ for THE). In post hoc paired Student's $t$-tests, ${ }^{\star} P<0.05$ and $\phi P<0.01$ compared with basal measurements.

or $(5 \beta-+5 \alpha$-THF $) /$ THE). However, VLCD did induce a fall in $5 \alpha$-reductase activity $(5 \alpha$-THF/cortisol $)$ and, during weight maintenance only, reduced $5 \beta$-reductase metabolism of cortisone (THE/cortisone) but not cortisol ( $5 \beta-\mathrm{THF} /$ cortisol).

Fewer measurements were performed in the starvation study, but there were no statistically significant differences from baseline in absolute excretion of cortisol or cortisol metabolites after $5 \%$ weight loss or after subjects were allowed to feed ad libitum. However, starvation did affect cortisol metabolism, with increases in cortisol/ cortisone and $5 \beta-/ 5 \alpha-\mathrm{THF}$ during starvation, which reverted to baseline values after subjects were allowed to feed ad libitum. The $5 \beta$-THE/cortisone ratio was also lower during the ad libitum diet than at baseline.

\section{Plasma cortisol}

CBG did not change during VLCD or starvation studies (Table 3). Plasma cortisol and its diurnal variation between $0900 \mathrm{~h}$ and $1815 \mathrm{~h}$ were not significantly affected by VLCD (Fig. 3). However, during starvation, plasma cortisol was markedly elevated both in the morning and evening compared with pre-starvation values (Fig. 3).

\section{Discussion}

These data show that acute weight loss (of $~ 10 \%$ ) in obese men induced by VLCD over 3 weeks is associated with a substantial decline in cortisol production together with evidence of reduced metabolism of cortisol and cortisone, by $5 \alpha$-reductase and $5 \beta$-reductase respectively, and no change in plasma cortisol. These findings are consistent with published evidence that activation of the HPA axis in obesity occurs as a compensatory response to increased peripheral clearance of cortisol $(7,8)$, particularly by A-ring reductases (9); thus, during calorie restriction, a decrease in peripheral cortisol clearance is associated with a compensatory fall in cortisol production to maintain a normal plasma cortisol. However, these effects of low calorie diet were acutely reversible when subjects returned to a diet where they were allowed to feed ad libitum, despite there being no regain of weight. This suggests that abnormalities in cortisol metabolism and HPA axis function in obesity are either only temporarily reversed by calorie restriction and/or weight loss in obesity, or are acutely responsive to nutritional status rather than to obesity per se.

More modest weight loss (of $\sim 5 \%$ ) induced more quickly by starvation appeared to show a different pattern of effects on cortisol. Fewer measurements were made during the starvation protocol, the time course of intervention was different, and the subjects were not well-matched with those in the calorie restriction study, so that direct comparison of the two groups is not appropriate. Nevertheless, in apparent contrast with men on VLCD, in starved subjects plasma cortisol rose and urinary cortisol metabolite excretion did not 
Table 3 Effects of short-term weight loss on urinary cortisol metabolite excretion and plasma CBG.

\begin{tabular}{|c|c|c|c|}
\hline Measurement & Phase of study & Starvation & VLCD \\
\hline Total cortisol metabolite & Maintained basal & $16.1 \pm 1.5$ & $15.8 \pm 1.1$ \\
\hline \multirow{4}{*}{ excretion (mg/day) } & $5 \%$ weight loss & $11.9 \pm 20.0$ & $13.4 \pm 0.7$ \\
\hline & $10 \%$ weight loss & & $9.8 \pm 1.8^{\star *}$ \\
\hline & Maintained weight loss & & $7.0 \pm 1.1^{\star *}$ \\
\hline & Ad libitum & $12.1 \pm 1.8$ & $13.1 \pm 1.7$ \\
\hline \multirow[t]{5}{*}{$5 \beta-\mathrm{THF} / 5 \alpha-\mathrm{THF}$} & Maintained basal & $0.52 \pm 0.07$ & $0.70 \pm 0.15$ \\
\hline & $5 \%$ weight loss & $0.77 \pm 0.09^{\star \star}$ & $0.75 \pm 0.12$ \\
\hline & $10 \%$ weight loss & & $0.83 \pm 0.12$ \\
\hline & Maintained weight loss & & $1.03 \pm 0.08$ \\
\hline & Ad libitum & $0.57 \pm 0.09$ & $0.98 \pm 0.21$ \\
\hline \multirow[t]{5}{*}{$(5 \beta-\mathrm{THF}+5 \alpha-\mathrm{THF}) / \mathrm{THE}$} & Maintained basal & $1.34 \pm 0.17$ & $2.71 \pm 0.72$ \\
\hline & $5 \%$ weight loss & $1.86 \pm 0.31$ & $2.75 \pm 1.30$ \\
\hline & $10 \%$ weight loss & & $1.91 \pm 0.18$ \\
\hline & Maintained weight loss & & $2.08 \pm 0.20$ \\
\hline & Ad libitum & $1.53 \pm 0.25$ & $1.90 \pm 0.21$ \\
\hline \multirow[t]{5}{*}{$5 \beta-\mathrm{THF} /$ cortisol } & Maintained basal & $15.7 \pm 2.4$ & $41.2 \pm 8.4$ \\
\hline & $5 \%$ weight loss & $15.4 \pm 2.5$ & $31.5 \pm 4.4$ \\
\hline & $10 \%$ weight loss & & $36.0 \pm 3.5$ \\
\hline & Maintained weight loss & & $26.9 \pm 2.9$ \\
\hline & Ad libitum & $10.6 \pm 1.0$ & $37.1 \pm 3.1$ \\
\hline \multirow[t]{5}{*}{$5 \alpha-$ THF/cortisol } & Maintained basal & $32.9 \pm 6.3$ & $70.5 \pm 17.1$ \\
\hline & $5 \%$ weight loss & $22.5 \pm 5.7$ & $51.0 \pm 13.1$ \\
\hline & $10 \%$ weight loss & & $47.8 \pm 7.6$ \\
\hline & Maintained weight loss & & $26.6 \pm 3.3^{* *}$ \\
\hline & Ad libitum & $22.0 \pm 4.7$ & $44.8 \pm 6.7$ \\
\hline \multirow[t]{5}{*}{ THE/cortisone } & Maintained basal & $56.7 \pm 6.1$ & $55.9 \pm 6.5$ \\
\hline & $5 \%$ weight loss & $48.3 \pm 6.0$ & $59.6 \pm 7.3$ \\
\hline & $10 \%$ weight loss & & $65.9 \pm 5.7$ \\
\hline & Maintained weight loss & & $34.7 \pm 6.7^{\star}$ \\
\hline & Ad libitum & $43.3 \pm 6.5^{\star}$ & $58.7 \pm 4.2$ \\
\hline \multirow[t]{5}{*}{ Cortisol/cortisone } & Maintained basal & $1.76 \pm 0.39$ & $1.24 \pm 0.08$ \\
\hline & $5 \%$ weight loss & $2.64 \pm 0.50^{*}$ & $1.46 \pm 0.10$ \\
\hline & $10 \%$ weight loss & & $1.53 \pm 0.15$ \\
\hline & Maintained weight loss & & $1.28 \pm 0.15$ \\
\hline & Ad libitum & $1.99 \pm 0.32$ & $1.36 \pm 0.15$ \\
\hline \multirow{4}{*}{$\mathrm{CBG}(\mu \mathrm{g} / \mathrm{ml})$} & Maintained basal & $32.4 \pm 2.2$ & $30.6 \pm 4.7$ \\
\hline & $5 \%$ weight loss & $41.8 \pm 6.0$ & $33.0 \pm 3.3$ \\
\hline & $10 \%$ weight loss & & $33.7 \pm 3.6$ \\
\hline & Maintained weight loss & $26.7 \pm 3.2$ & $22.2 \pm 4.0$ \\
\hline
\end{tabular}

Data are means \pm S.E.M.

Versus maintained basal measurement: ${ }^{\star} P<0.05 ;{ }^{\star \star} P<0.01 ;{ }^{\star \star \star} P<0.001$.

significantly fall. Starvation induced a relative increase in urinary free cortisol, and a shift in favour of $5 \beta$ rather than $5 \alpha$-reduction of cortisol. These features are in keeping with stress and 'central' activation of the HPA axis.

A few previous studies have assessed the HPA axis following weight loss, but have only examined plasma cortisol concentrations $(39-41)$. These data are broadly in keeping with our findings, since they suggest that weight loss induced by calorie restriction produces either no change or a marginal increase in plasma cortisol $(41,42)$ and has no effect on suppression of plasma cortisol by dexamethasone (40), while starvation induces more marked elevation in cortisol levels in saliva (39) and plasma $(43,44)$. The lack of change in $\mathrm{CBG}$ is consistent with previous studies of acute starvation (44) or high fat feeding in burned patients (45), although there may be an effect of high protein intake to increase CBG levels (46). To our knowledge, no previous studies have examined effects of weight loss on cortisol secretion rate or metabolism in humans.

The most striking finding in our data is the observation that total cortisol metabolite excretion falls substantially during weight loss with VLCD. We were unable to administer 'placebo' dietary manipulations, so that comparison is made with baseline measurements. Cortisol production might be expected to fall as subjects acclimatised to the study environment. However, it appears unlikely that such an 'order effect' explains these results. The stress response to a new environment is manifest as increased plasma cortisol especially in the evening, and usually resolves within $48 \mathrm{~h}$ (47); our subjects had basal measurements at the end of the first week of study and did not exhibit any fall in plasma cortisol later. Also, we included measurements during ad libitum feeding at the end of the dietary manipulations to show that the cortisol 


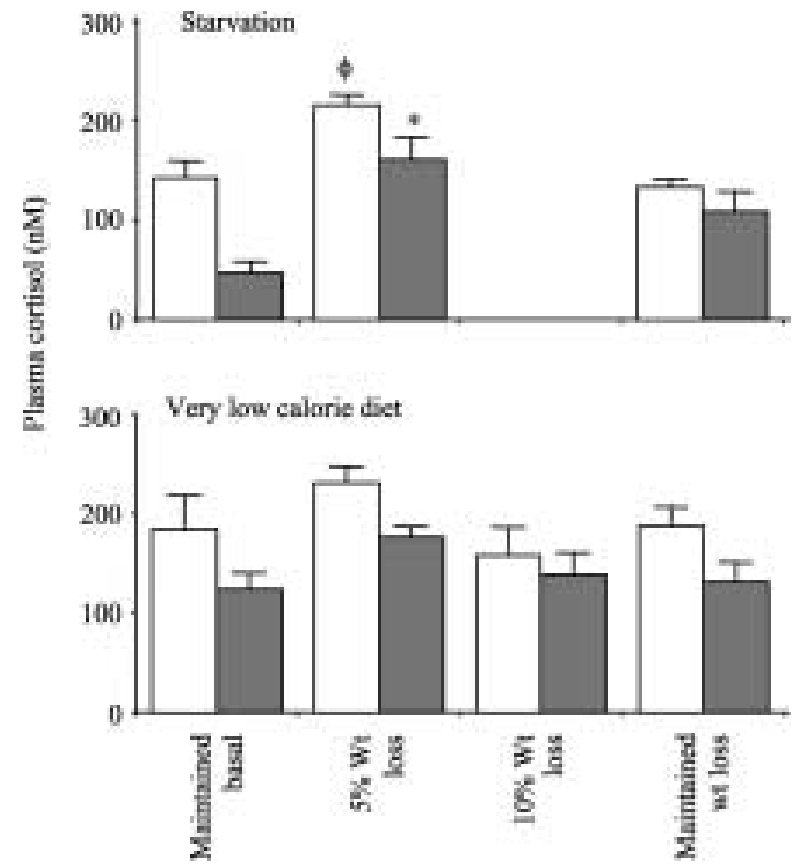

Figure 3 Plasma cortisol. Data are means \pm S.E.M. for $n=6$ subjects in the starvation study (upper panel) or the VLCD study (lower panel). By repeated measures ANOVA, differences were significant only following starvation $(P<0.001$ for $0930 \mathrm{~h}$ cortisol and $P<0.05$ for $1815 \mathrm{~h}$ cortisol). In post hoc paired Student's $t$-tests, ${ }^{\star} P<0.05$ and $\phi P<0.01$ compared with basal measurements at the same time of day.

measurements returned towards baseline with a return to unrestricted food intake. However, it is notable that, during the ad libitum period, participants did not actually gain weight (Table 2). This is probably because of self-imposed calorie restriction by the participants at the end of the study, because they were motivated by a desire to lose weight and maintain their weight loss. It is possible that the effects of weight loss are transient and that measurements would have reverted towards baseline even if formal calorie restriction had been maintained and weight loss continued. Nonetheless, this observation suggests that the influence of VLCD on the HPA axis is mediated by nutritional signals which alter in advance of changes in weight.

The cause of the activation of the HPA axis in obesity is contentious. The failure of many studies to document any consistent abnormality of central feedback or 'feed forward' control of the axis, together with the key observation that plasma cortisol levels are not elevated in obesity, has reinforced the hypothesis that activation of the axis is secondary to enhanced metabolic clearance of cortisol. The current study does not test this hypothesis directly, but the findings are consistent with it, since the reduction of cortisol production induced by VLCD was accompanied by small but significant changes in urinary ratios reflecting the flux of metabolites through different pathways of cortisol metabolism.
Alterations in peripheral cortisol metabolism in obesity have been characterised only recently. It appears that two discrete components contribute to enhanced metabolic clearance rate of cortisol: inactivation of cortisol by $5 \alpha$-reductase and $5 \beta$-reductase is enhanced $(9,10)$, while reactivation of cortisol from cortisone by 11 HSD1 in liver is impaired $(17,19,21)$. In contrast, however, intra-adipose reactivation of cortisone to cortisol by 11 HSD 1 is enhanced in obesity $(17,19$, 20). The changes in $5 \alpha$ - and $5 \beta$-reductases are detected as increased relative excretion of their products in urine (see Fig. 1). However, probably because of up-regulation of 11HSD1 in liver and down-regulation in adipose tissue, urinary cortisol/cortisone metabolite ratios are unpredictable in obesity, being higher when increased fat mass predominates (e.g. in women $(9,19))$ and lower perhaps when decreased hepatic 11HSD1 predominates $(17,21)$. Thus, changes in enzyme activity with weight loss may be easier to detect for $5 \alpha$ - and $5 \beta$-reductase than for 11HSD1. The same pattern of tissue-specific alterations in glucocorticoid metabolism has been described in Zucker obese rats (26). In these animals, when weight gain was prevented by adrenalectomy, alterations in glucocorticoid-metabolising enzymes largely resolved (27). Here, we found evidence for normalisation of $5 \alpha$ - and $5 \beta$-reductase with weight loss, but could not detect changes in 11HSD1. More detailed studies, for example measuring in vivo conversion of cortisone to cortisol $(17,19,21)$, using deuterated cortisol tracer (48) or taking adipose biopsies (17) would be required to exclude changes in 11HSD1 during weight loss. In the current studies, repeated adipose biopsies were not taken because we judged that the protocol was already sufficiently invasive for the subjects, and dynamic tests involving cortisone administration were not performed to avoid confounding effects of exogenous glucocorticoids during nutritional manipulation.

The mechanism for the increase in A-ring reductase activities in obesity, and normalisation of this abnormality with weight loss, is obscure. There are two isozymes of $5 \alpha$-reductase and both probably contribute to cortisol metabolism, since the type 1 predominates in liver while the type 2 inhibitor finasteride alters urinary cortisol metabolite excretion (49). Information on promoter regulation of these genes remains scanty and relates predominantly to sex steroid regulation $(50,51)$, so it is unclear whether they are transcriptionally controlled by 'nutrient' receptors such as peroxisome proliferator activating receptor (PPARs). Importantly, the present results suggest that abnormalities in cortisol metabolism in obesity are potentially reversible, but apparently only in the short term. Whether longer term weight loss achieved by less dramatic nutritional manipulation would reverse abnormalities in A-ring reductase activities and HPA axis function in obesity requires separate investigation. The current data suggest, however, that acute changes 
in nutritional status can alter cortisol metabolism in humans and that the signals for this process may not be closely associated with body fat content. More detailed dissection of metabolic signals associated with altered cortisol secretion and metabolism during nutritional manipulation is now justified.

The apparently discrepant changes in cortisol measurements when 5\% weight loss was induced by starvation or VLCD are intriguing. These results must be interpreted with caution as the two groups are not comparable in several respects. With complete starvation, we interpret the increased plasma cortisol levels as reflecting a stress response, which presumably obscures any tendency for cortisol production rate to fall with weight loss. With increased ACTH-dependent cortisol production, inactivation of cortisol to cortisone by 11 HSD 2 may be impaired $(52,53)$, resulting in elevated urinary free cortisol/cortisone (38). The elevation of $5 \beta-\mathrm{THF} / 5 \alpha$-THF in this circumstance is more difficult to explain, since increased cortisol production rate is usually associated with increased $5 \alpha$ THF excretion (54), but it may reflect a similar effect of weight loss to normalise $5 \alpha$-reductase activity as is observed in the $5 \alpha$-THF/cortisol ratio with VLCD. This might explain why total cortisol metabolite excretion is not increased during what we interpret as stressful activation of the HPA axis with starvation. Further, it appears that the HPA axis activation in response to starvation is relieved when subjects are allowed to feed ad libitum in advance of any regain of body weight. This may reflect a temporary response of the HPA axis to starvation, removal of the psychological stress of maintaining a starvation diet, or reversal of a direct signal of nutritional deprivation.

What implications do these results have for therapy in obesity? Clearly, the results in these acute studies are not generalisable to the dietary management of obese patients. Further, the participants here represent an unusual group of highly motivated and otherwise healthy individuals. Nonetheless, one might speculate that different cortisol responses to different dietary manipulations contributes to their success in improving the metabolic profile. Thus, the failure of acute starvation, and relative success of sustained low calorie diets, in inducing sustained weight loss, might conceivably reflect contrasting effects on cortisol production. If maintained in the longer term, the results could also provide an explanation for the clinical benefits of weight loss in hyperandrogenised women. Reduced ACTH-dependent cortisol production will also be accompanied by reduced adrenal androgen synthesis, probably contributing to beneficial reproductive function with weight loss in polycystic ovarian disease (55). These results suggest that interventions which normalise cortisol metabolism in obesity, including $5 \alpha$-reductase inhibitors, should be tested for their contribution to normalisation of cortisol and androgen production, and potential normalisation of metabolic profile in obesity. Finally, these data raise the intriguing possibility that peripheral cortisol metabolism is acutely regulated by nutritional intake, and that tissue cortisol exposure is modified as part of the physiological response to variations in nutrient availability. In this light, the disruption of cortisol metabolism in obese individuals may represent a maladaptive physiological response.

\section{Acknowledgements}

This work was supported by grants from the British Heart Foundation (to BRW), from Slimming World, Alfreton, UK and the Scottish Executive Environment and Rural Affairs Department (to RJS). We are grateful to Alison Ayres, Jill Campbell and Denis Marino for technical assistance.

\section{References}

1 Bjorntorp P. Endocrine abnormalities in obesity. Diabetes Reviews $1997552-68$.

2 Marin P, Darin M, Amemiya T, Andersson B, Jern S \& Bjorntorp P. Cortisol secretion in relation to body fat distribution in obese premenopausal women. Metabolism 19924 1882-1886.

3 Pasquali R, Cantobelli S, Casimirri F, Capelli M, Bortoluzzi L, Flamia $\mathrm{R}$ et al. The hypothalamic-pituitary-adrenal axis in obese women with different patterns of body fat distribution. Journal of Clinical Endocrinology and Metabolism $1993 \mathbf{7 7}$ $341-346$.

4 Rosmond R, Dallman MF \& Bjorntorp P. Stress-related cortisol secretion in men: relationships with abdominal obesity and endocrine, metabolic and haemodynamic abnormalities. Journal of Clinical Endocrinology and Metabolism 199883 1853-1859.

5 Ljung T, Andersson B, Bengtsson B, Bjorntorp P \& Marin P. Inhibition of cortisol secretion by dexamethasone in relation to body fat distribution: a dose-response study. Obesity Research 19964 277-282.

6 Walker BR, Soderberg S, Lindahl B \& Olsson T. Independent effects of obesity and cortisol in predicting cardiovascular risk factors in men and women. Journal of Internal Medicine $2000 \mathbf{2 4 7}$ 198-204.

7 Strain GW, Zumoff B \& Strain JJ. Cortisol production in obesity. Metabolism: Clinical and Experimental 198029 980-985.

8 Lottenberg SA, Giannella-Neto D, Derendorf H, Rocha M, Bosco A, Carvalho SV et al. Effect of fat distribution on the pharmacokinetics of cortisol in obesity. International Journal of Clinical Pharmacology and Therapeutics $199836501-505$.

9 Andrew R, Phillips DIW \& Walker BR. Obesity and gender influence cortisol secretion and metabolism in man. Journal of Clinical Endocrinology and Metabolism 199883 1806-1809.

10 Fraser R, Ingram MC, Anderson NH, Morrison C, Davies E \& Connell JMC. Cortisol effects on body mass, blood pressure, and cholesterol in the general population. Hypertension 199933 $1364-1368$.

11 Stewart PM, Shackleton CHL, Beastall GH \& Edwards CRW. 5alpha-reductase activity in polycystic ovarian syndrome. Lancet $1990335431-433$.

12 Stewart PM \& Krozowski ZS. 11Beta hydroxysteroid dehydrogenase. Vitamins and Hormones 199957 249-324.

13 Seckl JR \& Walker BR. 11 $\beta$-Hydroxysteroid dehydrogenase type 1 - a tissue-specific amplifier of glucocorticoid action. Endocrinology $20011421371-1376$.

14 Kotelevtsev YV, Holmes MC, Burchell A, Houston PM, Scholl D, Jamieson PM et al. 11ß-Hydroxysteroid dehydrogenase type 1 
knockout mice show attenuated glucocorticoid inducible responses and resist hyperglycaemia on obesity and stress. PNAS 199794 14924-14929.

15 Morton NM, Holmes MC, Fievet C, Staels B, Tailleux A, Mullins JJ et al. Improved lipid and lipoprotein profile, hepatic insulin sensitivity, and glucose tolerance in 11ß-hydroxysteroid dehydrogenase type 1 null mice. Journal of Biological Chemistry 2001276 41293-41300.

16 Masuzaki H, Paterson J, Shinyama H, Morton NM, Mullins JJ, Seckl JR et al. A transgenic model of visceral obesity and the metabolic syndrome. Science $2001 \mathbf{2 9 4} 2166-2170$.

17 Rask E, Olsson T, Soderberg S, Andrew R, Livingstone DEW, Johnson $\mathrm{O}$ et al. Tissue-specific dysregulation of cortisol metabolism in human obesity. Journal of Clinical Endocrinology and Metabolism 200186 1418-1421.

18 Lindsay RS, Tataranni A, Permana P, Livingstone DEW, Wake DJ \& Walker BR. Subcutaneous adipose 11 $\beta$-hydroxysteroid dehydrogenase type 1 activity and mRNA levels are associated with adiposity and insulinaemia in Pima Indians and Caucasians. Journal of Clinical Endocrinology and Metabolism $2003 \mathbf{8 8}$ $2738-2744$.

19 Rask E, Walker BR, Soderberg S, Livingstone DEW, Eliasson M, Johnson $\mathrm{O}$ et al. Tissue-specific changes in peripheral cortisol metabolism in obese women increased adipose $11 \beta$-hydroxysteroid dehydrogenase type 1 activity. Journal of Clinical Endocrinology and Metabolism 200287 3330-3336.

20 Paulmyer-Lacroix O, Boullu S, Oliver C, Alessi M-C \& Grino M. Expression of the mRNA coding for $11 \beta$-hydroxysteroid dehydrogenase type 1 in adipose tissue from obese patients: an in situ hybridization study. Journal of Clinical Endocrinology and Metabolism $2002872701-2705$.

21 Stewart PM, Boulton A, Kumar S, Clark PMS \& Shackleton CHL. Cortisol metabolism in human obesity: impaired cortisone-cortisol conversion in subjects with central adiposity. Journal of Clinical Endocrinology and Metabolism $1999841022-1027$.

22 Walker BR, Connacher AA, Lindsay RM, Webb DJ \& Edwards CRW. Carbenoxolone increases hepatic insulin sensitivity in man: a novel role for 11-oxosteroid reductase in enhancing glucocorticoid receptor activation. Journal of Clinical Endocrinology and Metabolism $1995 \mathbf{8 0} 3155-3159$.

23 Bujalska IJ, Kumar S \& Stewart PM. Does central obesity reflect 'Cushing's disease of the omentum'? Lancet $1997 \mathbf{3 4 9}$ $1210-1213$.

24 Alberts P, Engblom L, Edling N, Forsgren M, Klingstrom G, Larsson $\mathrm{C}$ et al. Selective inhibition of 11beta-hydroxysteroid dehydrogenase type 1 decreases blood glucose concentrations in hyperglycaemic mice. Diabetologia 200245 1528-1532.

25 Andrews RC, Rooyackers O \& Walker BR. Effects of the 11 betahydroxysteroid dehydrogenase inhibitor carbenoxolone on insulin sensitivity in men with type 2 diabetes. Journal of Clinical Endocrinology and Metabolism $2003 \mathbf{8 8} 285-291$.

26 Livingstone DEW, Jones GC, Smith K, Andrew R, Kenyon CJ \& Walker BR. Understanding the role of glucocorticoids in obesity: tissue-specific alterations of corticosterone metabolism in obese Zucker rats. Endocrinology 2000141 560-563.

27 Livingstone DEW, Kenyon CJ \& Walker BR. Mechanisms of dysregulation of 11ß-hydroxysteroid dehydrogenase type 1 in Zucker obese rats. Journal of Endocrinology 2000167 533-539.

28 Stubbs RJ, O'Reilly LM, Johnstone AM, Franklin MF \& Reid C. Description and evaluation of an experimental model to examine changes in qualitative and quantitative feeding behaviour in humans. European Journal of Clinical Nutrition 199953 13-21.

29 Black AE, Coward WA, Cole TJ \& Prentice AM. Human energy expenditure in affluent societies: an analysis of 574 doublylabelled water measurements. European Journal of Clinical Nutrition $19965072-92$.

30 Spurr GB, Prentice AM, Murgatroyd PR, Goldberg GR, Reina JC \& Christman NT. Energy expenditure from minute-by-minute heartrate recording: comparison with indirect calorimetry. American Journal of Clinical Nutrition $1988 \mathbf{4 8} 552-559$.
31 Ceesay SM, Prentice AM, Day KC, Murgatroyd PR, Goldberg GR \& Scott W. The use of heart rate monitoring in the estimation of energy expenditure: a validation study using indirect whole body calorimetry. British Journal of Nutrition 198971 175-186.

32 Fuller NJ, Jebb SA, Laskey MA, Coward WA \& Elia M. Four-compartment model for the assessment of body composition in humans: comparison with alternative methods and evaluation of the density and hydration of fat-free mass. Clinical Science $199282687-693$.

33 Pullicino E, Coward WA, Stubbs RJ \& Elia M. Bedside and field methods for assessing body composition: comparison with the deuterium dilution technique. European Journal of Clinical Investigation $1990 \mathbf{4 0} 753-762$.

34 McConway MG \& Chapman RS. Development and evaluation of a simple, direct, solid-phase radioimmunoassay of serum cortisol from readily available reagents. Clinica Chimica Acta $1986 \mathbf{1 5 8}$ 59-70.

35 Best R \& Walker BR. Additional value of measurement of urinary cortisone and unconjugated cortisol metabolites in assessing the

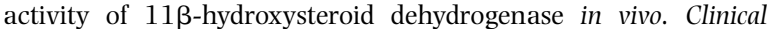
Endocrinology $199747231-236$.

36 Zumoff B, Fukushima DK \& Hellman L. Intercomparison of four methods for measuring cortisol production. Journal of Clinical Endocrinology and Metabolism 197438 169-175.

37 Ulick S, Tedde R \& Wang JZ. Defective ring A reduction of cortisol as the major metabolic error in the syndrome of apparent mineralocorticoid excess. Journal of Clinical Endocrinology and Metabolism 1992 74 593-599.

38 Palermo M, Shackleton CHL, Mantero F \& Stewart PM. Urinary free cortisone and the assessment of 11 beta-hydroxysteroid dehydrogenase activity in man. Clinical Endocrinology $1996 \mathbf{4 5}$ 605-611.

39 Fichter MM, Pirke K-M \& Holsboer F. Weight loss causes neuroendocrine disturbances: experimental study in healthy starving subjects. Psychiatry Research 198617 61-72.

40 Yanovski SZ, Yanovski JA, Gwirtsman HE, Bernat A, Gold PW \& Chrousos GP. Normal dexamethasone suppression in obese binge and nonbinge eaters with rapid weight loss. Journal of Clinical Endocrinology and Metabolism $1993 \mathbf{7 6}$ 675-679.

41 Wabitsch M, Hauner H, Heinze E, Bockmann A, Benz R, Mayer H et al. Body fat distribution and steroid hormone concentrations in obese adolescent girls before and after weight reduction. Journal of Clinical Endocrinology and Metabolism 199580 3469-3475.

42 Hainer V, Stich V, Kunesova M, Parizkova J, Zak A \& Wernischova V. Effect of 4-wk treatment of obesity by very-lowcalorie diet on anthropometric, metabolic, and hormonal indexes. American Journal of Clinical Nutrition 199256 281S-282S.

43 Haluzik M, Matoulek M, Svacina S, Hilgertova J \& Haas T. The influence of short-term fasting on serum leptin levels, and selected hormonal and metabolic parameters in morbidly obese and lean females. Endocrine Research 200127 251-260.

44 Fraser DA, Thoen J, Selvaag A-M, Djoseland O, Forre O \& Kjeldsen-Kragh J. A preliminary study of circadian serum cortisol concentrations in response to a 72-hour fast in rheumatoid arthritis patients not previously treated with corticosteroids. Clinical Rheumatology 200120 85-87.

45 Bernier J, Jobin N, Emptoz-Bonneton A, Pugeat MM \& Garrel DR. Decreased corticosteroid-binding globulin in burn patients: relationship with interleukin- 6 and fat in nutritional support. Critical Care Medicine 199826 452-460.

46 Anderson KE, Rosner W \& Khan MS. Diet-hormone interactions: protein/carbohydrate ratio alters reciprocally the plasma levels of testosterone and cortisol and their respective binding globulins in man. Life Sciences $1987 \mathbf{4 0} 1761-1768$.

47 Kaye TB \& Crapo L. The Cushing syndrome: an update on diagnostic tests. Annals of Internal Medicine 1990112 434-444.

48 Andrew R, Smith K, Jones GC \& Walker BR. Use of multideuterated cortisol to distinguish activities of $11 \beta$-hydroxysteroid dehydrogenases in vivo in man. Journal of Clinical Endocrinology and Metabolism 200287 277-285. 
49 Imperato-McGinley J, Shackleton C, Orlic S \& Stoner E. C19 and C21 5beta/5alpha metabolite ratios in subjects treated with the 5alpha-reductase inhibitor finasteride: comparison of male pseudohermaphrodites with inherited 5alpha-reductase deficiency. Journal of Clinical Endocrinology and Metabolism 1990 $70777-782$.

50 Pratis K, O’Donnell L, Ooi GT, Stanton PG, McLachlan RI \& Robertson DM. Differential regulation of rat testicular $5 \alpha$-reductase type 1 and 2 isoforms by testosterone and FSH. Journal of Endocrinology $2003176393-403$.

51 Matsui D, Sakari M, Sato T, Murayama A, Takada I, Kim M et al. Transcriptional regulation of the mouse steroid $5 \alpha$-reductase type II gene by progesterone in brain. Nucleic Acids Research 200230 1387-1393.

52 Ulick S, Wang JZ, Blumenfeld JD \& Pickering TG. Cortisol inactivation overload: a mechanism of mineralocorticoid hypertension in the ectopic adrenocorticotropin syndrome. Journal of Clinical Endocrinology and Metabolism 1992 74 963-967.
53 Walker BR, Campbell JC, Fraser R, Stewart PM \& Edwards CRW. Mineralocorticoid excess and inhibition of $11 \beta$-hydroxysteroid dehydrogenase in patients with ectopic ACTH syndrome. Clinical Endocrinology 199227 483-492.

54 Phillipou G. Investigation of urinary steroid profiles as a diagnostic method in Cushing's syndrome. Clinical Endocrinology 1982 16 433-439.

55 Pasquali R, Antenucci D, Casimirri F, Venturoli S, Paradisi R, Fabbri R et al. Clinical and hormonal characteristics of obese amenorrheic hyperandrogenic women before and after weight loss. Journal of Clinical Endocrinology and Metabolism 1989 68 173-179.

Received 11 July 2003

Accepted 26 September 2003 